\title{
A Continuum Approach to Understanding Changes in the ENSO-Indian Monsoon Relationship
}

\author{
Justin Schulte, ${ }^{\mathrm{a}}$ Frederick Policelli, ${ }^{\mathrm{b}}$ And Benjamin Zaitchik ${ }^{\mathrm{c}}$ \\ ${ }^{\text {a }}$ Science Systems and Applications, Inc., Lanham, Maryland \\ ${ }^{\mathrm{b}}$ NASA Goddard Space Flight Center, Greenbelt, Maryland \\ ${ }^{\mathrm{c}}$ Johns Hopkins University, Baltimore, Maryland
}

(Manuscript received 15 January 2020, in final form 27 October 2020)

\begin{abstract}
It is well documented that the relationship between the El Niño-Southern Oscillation (ENSO) and the Indian summer monsoon changes on interdecadal time scales, yet an explanation for the variations is still a subject of debate. Here, using a continuum framework based on one-point partial correlation maps, we show that the ENSO-Indian rainfall relationship is influenced by the gradient of sea surface temperature anomalies (SSTA) across the Niño-3 region. Based on this identified SSTA pattern, a simple trans-Niño-3 (TN3) index is created that explains up to $50 \%$ of all-India rainfall variability during the mid- to late monsoon season after the 1960s. It is also shown that the influence of the TN3 pattern on the relationship between common ENSO metrics and all-India rainfall is strongest during the August-September (AS) monsoon subseason and weakest during the June-July subseason. The TN3 pattern accounts for up to $80 \%$ of the change and sign reversal in the AS Niño-1+2-all-India rainfall relationship in recent decades. The 1940s coincides with the intensification of the TN3 pattern and its influence. As the TN3 index is nearly orthogonal to the Niño-3 index, and both are strongly correlated with all-India rainfall, the strengthening TN3 influence must be systematically associated with the weakening Niño-3-all-India relationship in recent decades. This work supports arguments that recent changes in the ENSO-Indian rainfall relationship are not solely related to noise.
\end{abstract}

KEYWORDS: Asia; Seasonal forecasting; Statistical forecasting; Decadal variability

\section{Introduction}

The El Niño-Southern Oscillation (ENSO) is an important driver of the Indian summer monsoon, with El Niño events tending to produce droughts and La Niña events preferentially producing monsoon surpluses (Kumar et al. 2006). Because of the strong influence of ENSO, ENSO metrics such as the Niño-3 and Niño-3.4 indices (Kumar et al. 1999) are often incorporated into empirical monsoon forecasts. However, the ENSO-Indian summer monsoon relationship is nonstationary (Krishnamurthy and Goswami 2000; Torrence and Webster 1999), rendering forecasting the Indian summer monsoon based on ENSO a challenging endeavor (Kumar et al. 2006). An additional difficulty is the nonstationary behavior of ENSO itself, with previous studies documenting changing dominant periodicities (Kestin et al. 1998) and nonlinear characteristics (Wu and Hsieh 2003; An and Jin 2004; An 2004; An et al. 2005; An 2009; Santoso et al. 2013).

Recognizing that understanding the cause of the fluctuating ENSO-Indian summer monsoon relationship could improve monsoon forecasts, many investigators have sought an explanation for the fluctuations. However, the cause is the subject of an ongoing debate within the scientific community, with some studies adopting a deterministic perspective and other studies offering indeterministic frameworks. In the deterministic perspective, the ENSO-Indian summer monsoon relationship is modulated by other climate phenomena such as the Atlantic multidecadal oscillation (Lu et al. 2006), tropical Atlantic sea surface temperatures (SSTs; Kucharski et al. 2007, 2009; Chen

Corresponding author: Justin Schulte, jschulte972@gmail.com et al. 2010), Indian Ocean dipole (Ashok et al. 2001, 2004), and changes in ENSO characteristics like shifts from eastern to central Pacific flavors (Fan et al. 2017). These deterministic frameworks suggest that incorporating information about ENSO flavors (Johnson 2013) and other teleconnection patterns could help determine when ENSO-based Indian summer monsoon forecasts will falter. On the contrary, other studies suggest that the changes are related to statistical undersampling (Cash et al. 2017) or noise (Gershunov et al. 2001). In a recent study, (Yun and Timmermann 2018) found that the changes are consistent with a stochastically perturbed ENSO signal, precluding the prediction of ENSO-based forecast error. More specifically, (Yun and Timmermann 2018) found that variations in the Niño-3-Indian rainfall sliding correlation time series are too small to be distinguishable from variations typically associated with noise.

Although previous work has identified a relationship between ENSO flavors and the Indian monsoon (Fan et al. 2017), predicting Indian rainfall using such information would require a suitable index that can capture the specific ENSO flavor most relevant to the Indian summer monsoon. There are many recent studies that have proposed new ENSO indices to quantify the strength and evolution of the central Pacific (CP) and east Pacific (EP) El Niño event types (Ashok et al. 2007; Kao and Yu 2009; Kug et al. 2009; Ren and Jin 2011; Yu and Kim 2011; Takahashi et al. 2011; Chen et al. 2013; Wang et al. 2018). One problem with these indices is that they only partitioned ENSO into two types of flavors, whereas SST patterns across the equatorial Pacific belong to a continuum of patterns (Johnson 2013) comprising CP, EP, and mixed ENSO flavors. This problem is relevant to the Indian summer monsoon because the preferred pattern influencing Indian rainfall may not 
be strictly consistent with a CP ENSO flavor (Fan et al. 2017). Furthermore, the construction of the EP and CP indices often involved advanced techniques like empirical orthogonal function (EOF) analysis, which has been shown to extract statistical patterns that may not represent physical patterns because physical patterns are not necessarily orthogonal (Dommenget and Latif 2002).

The limitations of these proposed indices with respect to Indian monsoon applications are that they are derived independently from data on the monsoon and therefore are not optimized to maximally explain Indian precipitation variability. For example, Fan et al. (2017) used the joint regressionEOF CP index to relate ENSO flavors to June-September rainfall and Kumar et al. (2006) suggested that drought-free El Niño years are associated with the trans-Niño pattern whose strength and evolution is measured using the trans-Niño index (TNI; Trenberth and Stepaniak 2001), an index closely tracking the second leading mode of SSTA variability across the equatorial Pacific (Kumar et al. 2006). However, those indices were derived independently of the Indian monsoon and may not describe the precise pattern most strongly related to Indian summer rainfall.

One simple yet powerful way to remedy this drawback is to adopt a continuum framework in which atmospheric or oceanic patterns are assumed to fall on a continuum of patterns (Franzke and Feldstein 2005; Johnson and Feldstein 2010; Johnson 2013). Under this framework, an optimal pattern for explaining precipitation variability can be derived using one-point correlation or composite plots. This approach was successful for other studies focusing on precipitation and temperature variability across other regions. Using composite plots of daily sea level pressure (SLP) anomalies, Schulte et al. (2017a) identified an SLP dipole pattern that explains more streamflow and precipitation variability (Schulte et al. 2017b) across the Northeast United States than the well-known PacificNorth American Pattern and North Atlantic Oscillation. In a similar study, Schulte and Lee (2019) used the continuum approach to derive a $500-\mathrm{hPa}$ geopotential height dipole index that explains up to $80 \%$ of wintertime temperature variability across the Northeast United States, which is much more than what the commonly used Arctic Oscillation index can explain. Given these successes, one may wonder if the continuum approach can help understand changes in the ENSO-Indian monsoon relationship.

In this study, we adopt a continuum approach to understanding changes in the Indian monsoon-ENSO relationship, building upon previous work assessing the determinism of ENSO-Indian monsoon relationship variations. This approach leads to the definition of a new index-the trans-Niño-3 (TN3)-index designed to optimally explain Indian rainfall variability.

\section{Data}

Global sea surface temperature fields from 1871 to 2016 were based on the Hadley Centre Global Sea Ice and Sea Surface Temperature dataset (Rayner et al. 2006). The data at each grid point were converted to monthly anomalies by subtracting 1871-2016 monthly means from the corresponding monthly values. The Niño-1+2, Niño-3, Niño-3.4, and Niño-4 indices from 1871 to 2016 (available at: https://www.esrl. noaa.gov/psd/gcos_wgsp/Time series/Data/nino34.long.data, last access: 15 March 2019) were used to characterize the strength and evolution of ENSO. A simple trans-Niño index like the one proposed by Trenberth and Stepaniak (2001) was also used to the measure the strength and evolution of $\mathrm{CP} \mathrm{El}$ Niño. We defined the index as the normalized Niño-4 index minus the normalized Niño-1+2 index without using a 5-month running mean as Trenberth and Stepaniak (2001) initially proposed. The reason for not using the 5-month running mean is that seasonal averaging was performed later in our correlation analyses.

The National Center for Atmospheric Research (NCEP) reanalysis (Kalnay et al. 1996) 500-hPa omega data were used to characterize large-scale subsidence, which is important to the occurrence of droughts. Regions of large-scale horizontal divergence were detected using NCEP reanalysis velocity potential (VP) fields at the 200-hPa level. Sea level pressure (SLP) fields based on NCEP reanalysis were used to identify the surface circulation patterns associated with various ENSO metrics. The 500-hPa omega, 200-hPa VP, and SLP data were converted to anomalies using 1979-2016 monthly means.

The all-India rainfall (AIR) time series (Parthasarathy et al. 1994) was used to understand the temporal behavior of the Indian summer monsoon. These data were extracted from the Indian Institute of Tropical Meteorology website (https://www. tropmet. res.in/DataArchival-51-Page, last access: 15 March 2019). The monthly AIR time series was constructed by averaging precipitation data corresponding to meteorological subdivisions that partition the India subcontinent (Parthasarathy et al. 1994). Like the ENSO time series, the AIR time series was converted into an anomaly time series by subtracting 1871-2016 monthly means from the individual monthly values.

\section{Methods}

\section{a. Correlation and partial correlation analyses}

Pearson correlation coefficients were computed between climate indices and AIR anomalies to measure the linear relationship strength between them. Furthermore, changes in the relationship were quantified using 20- and 50-yr sliding correlation analyses, which involved segmenting the data into 20 - or 50 -yr intervals and computing the correlation coefficients between climate indices and AIR anomalies in each interval. The correlation coefficients were computed between seasonally averaged AIR anomalies and climate indices for different Indian monsoon subseasons defined as consecutive 2-month periods falling within the standard JuneSeptember Indian summer monsoon season. The June-July (JJ) subseason was the early monsoon subseason, whereas the July-August (JA) and August-September (AS) subseasons were the mid and late monsoon subseasons. Other seasons like July-September (JAS) and June-September (full) were also considered. This approach afforded the opportunity to understand within-season differences of the ENSO teleconnection. 
The Pearson correlation coefficients determined the degree to which AIR anomalies were related to ENSO through a linear prediction model of the following form:

$$
\mathrm{AIR}=a \times \mathrm{ENSO}+b+\alpha,
$$

where $a$ and $b$ are regression coefficients determined by least squares regression. The residual term $\alpha$, defined as the observed AIR anomaly minus the predicted AIR anomaly, represents deviations from the linear ENSO signal. As suggested by previous work, changes in the AIR-ENSO relationship could be random (Yun and Timmerman 2018), which would mean that $\alpha$ is noise that cannot be predicted by any other explanatory variable. The likelihood that this null hypothesis of noise is true was assessed in this study using a variety of approaches.

In the first approach, we evaluated whether changes in the linearity of the ENSO-AIR relationship was related to changes in the ENSO-AIR relationship, as commonly quantified using the Pearson correlation coefficient. It was recognized that the Pearson correlation coefficient calculated between two time series would be less than one even if there was a one-to-one nonlinear association between them. To determine if the linearity of the ENSO-AIR relationship changed and contributed to the linear ENSO-AIR relationship variations, we computed a nonlinearity index defined as

$$
L_{x y} \equiv\left|r_{x y}-r_{x y}^{S}\right|
$$

where $r_{x y}^{S}$ is the Spearman rank coefficient. If there was a significant difference between the Pearson and the Spearman rank coefficients, then the AIR-ENSO relationship was deemed nonlinear, meaning that a part of $\alpha$ was related to the invalidity of the linear model.

The statistical significance of the calculated nonlinearity indices was assessed using Monte Carlo methods as follows: First, 1000 pairs of red noise process realizations were generated, where each pair comprised a realization with lag-1 autocorrelation equal to AIR anomalies and one with lag-1 autocorrelation coefficient equal to that of the ENSO index in question. The length of each realization was equal to 20 because the analysis was based on 20-yr (20-point) time intervals. A null distribution was constructed by calculating the linearity index for each pair. The $95 \%$ percentile of this null distribution was then calculated to estimate the critical level of the test. This test determined if the nonlinearity index is larger than that typically expected from random time series.

The second approach to understanding the AIR-ENSO relationship was to determine if there is another explanatory variable that could partially explain the variance of the residuals in Eq. (1). To make such a determination, we adopted a continuum perspective (Franzke and Feldstein 2005; Johnson and Feldstein 2010; Johnson 2013) in which SST patterns were viewed as belonging to a continuum instead of a small set of discrete patterns. To find the SST pattern belonging to the continuum that most strongly correlates with AIR residuals, partial correlation coefficients between AIR and global SSTA were calculated using the following formula:

$$
r_{x y, z}=\frac{r_{x y}-r_{x z} r_{y z}}{\sqrt{\left(1-r_{x z}^{2}\right)\left(1-r_{y z}^{2}\right)}}
$$

where $r_{x y}$ is the simple Pearson correlation coefficient between $x$ and $y$. The third variable $(z)$ was called the control variable, which was mainly the Niño-3 index in this study for reasons discussed below. More specifically, if the partial correlation between AIR and SSTA was found to be weak, then SSTA at that grid point does not explain additional AIR variability beyond what ENSO can explain. By definition of the partial correlation coefficient, any correlation pattern arising from one-point partial correlation maps with the Niño-3 as the control variable was unrelated (orthogonal) to the Niño-3 index. The reason is that the partial correlation analysis identifies the SST pattern contributing to deviations (residuals) from the Niño-3 signal that are statistically constrained in a linear regression analysis to be uncorrelated to the Niño-3 index (i.e., the predictor).

The choice for using the Niño-3 index as the control variable was motivated by recent studies that used the Niño-3 index to understand ENSO-AIR relationship changes. Another reason for using the Niño-3 index over the Niño-3.4 is that it well characterizes canonical ENSO events (Lee and McPhaden 2010), and does not overlap with the Niño-4 region that is often used in measuring the strength of CP El Niño events (Lee and McPhaden 2010). Thus, using the Niño-3 index allowed us to better quantify deviations from the canonical ENSO signal. Nevertheless, results obtained using the Niño-3.4 index were found to be like those obtained using Niño-3 index.

In addition to correlating the ENSO indices to AIR anomalies, we also correlated the ENSO indices to residual AIR time series created through the least squares regression method. For example, an AIR residual time series for the AS subseason was obtained by constructing a linear regression model with the AS Niño-3 index as the predictor and the AS AIR time series as the predictand. These residual time series were created for each subseason individually and for different time periods depending on the analysis. For example, if the analysis was conducted for the 1979-2016 period, then the linear regression models were only constructed using data in that time period. For the sliding correlation analysis, which was based on the 1871-2016 period, a single linear regression model was constructed using all available data for the subseason in question so that all the residuals were based on a static ENSO signal.

\section{b. Arcwise test for statistical significance}

The statistical significance of sliding correlation coefficients was assessed more rigorously in this study than in previous studies analyzing the ENSO-Indian rainfall relationship. It was recognized that the standard (pointwise) approach of individually assessing the statistical significance of correlation coefficients has some drawbacks. First, even two realizations of a white noise process were found to be significantly correlated by chance (Fig. 1). Furthermore, statistically significant correlation coefficients were found to occur in clusters or contiguous pointwise significance arcs (black segments in Fig. 1) reflecting 
(a)

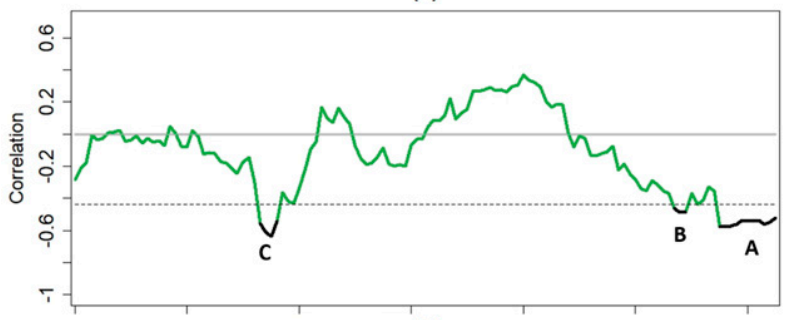

(b)

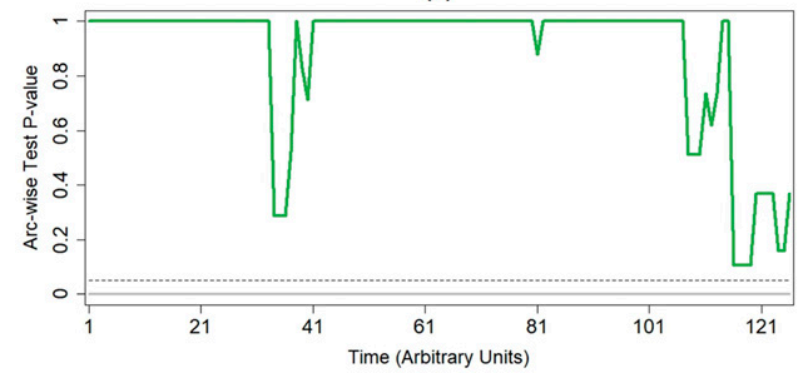

FIG. 1. 20-point sliding correlation between two realization of a white noise process. The $5 \%$ pointwise significance $\operatorname{arcs} \mathrm{A}, \mathrm{B}$, and $\mathrm{C}$ are depicted by the black segments, and the dotted line is the critical level of the pointwise test applied at the 5\% significance level. (b) Mean arcwise test $p$ value associated with the correlation coefficients in (a). The mean arcwise test $p$ value were obtained by applying the arcwise test using pointwise significance levels equal to $0.01,0.05,0.1$, and 0.15 .

the autocorrelation structure of the sliding correlation time series. The autocorrelation structure was related to how the correlation coefficients were computed using adjacent segments only differing by a single data value. Thus, an arcwise test was developed to reduce the number of spurious arcs arising from the pointwise test, enhancing the confidence in our findings. The arcwise test was based on the cumulative areawise and arcwise tests recently developed for statistical hypotheses in wavelet analysis (Schulte 2016, 2019). These tests have been shown to offer strong control over false positives while also being liberal in deeming truly significant features as significant (Schulte 2019).

The actual arc length test was performed as follows: For a fixed pointwise significance level, all pointwise significance arcs were extracted, and the corresponding arc lengths were computed, where arclength was defined as the number of points composing the arcs. The second step was to compare the computed arc lengths to a null distribution of arc lengths obtained from Monte Carlo methods. In the Monte Carlo approach, 1000 pairs of red noise process realizations were generated, where the lag-1 autocorrelation coefficient of one member of the pair was equal to that of the first input time series and the lag- 1 autocorrelation coefficient of the other was equal to that of the second input time series. Then, for each pair, the sliding correlation time series was computed, and the pointwise significance arcs were identified. The length of all pointwise significance arcs was computed, resulting in a null distribution of arclengths for a specified pointwise significance level. A contiguous arc was said to be arcwise significant at the $5 \%$ level if it exceeded the 95th percentile of the null distribution. Every point composing an arc was deemed arcwise significant if the arc length exceeded the critical level of the test. Recognizing that the results could be sensitive to the chosen pointwise significance level, the steps outlined above were performed at the $0.01,0.05,0.1$, and 0.15 pointwise significance levels. The correlation coefficient associated with a point was then said to be (cumulative) arcwise significant at the $5 \%$ level if the arcwise test $p$ value averaged across all pointwise significance levels was less than 0.05 . Points not located in pointwise significance arcs were assigned a value of 1 so that a mean arcwise test $p$ value of 1 meant that the correlation coefficient associated with a point was not pointwise significance at the $0.01,0.05,0.1$, and 0.15 pointwise significance levels.

As shown in the Fig. 1b, the application of the cumulative arcwise test eliminated the spurious pointwise significance arcs labeled A, B, and C in Fig. 1a. The mean arcwise test $p$ value associated with A, as an example, is greater than 0.05 (Fig. 1b). More detailed calculations about the performance of the arcwise test can be found in appendix.

\section{c. Wavelet analysis}

The dominant modes of variability embedded in time series were extracted using a wavelet analysis. The wavelet power spectra of time series were constructed using the Morlet wavelet, as it is commonly used in climate studies because it balances time and frequency localization. The statistical significance of the wavelet power was assessed using a cumulative areawise and arcwise test (Schulte 2019). Whereas the cumulative areawise test identified regions of statistical significance in general, the cumulative arcwise was used to identify periodicities in the time series. The statistical hypothesis tests were applied at the 5\% area- or arcwise significance level using pointwise significance levels varying from 0.02 to 0.18 incrementally by 0.02 . This choice was found to be associated with good statistical power (Schulte 2019). These tests were chosen over the standard pointwise test (Torrence and Compo 1998) because that test can be associated with many false positive results.

\section{Results}

\section{a. Sliding correlation time series}

Shown in Fig. 2a is the 20-yr sliding correlation between AIR and Niño-3 indices for the JJ, JA, and AS subseasons. While the correlation between the Niño-3 index and AIR anomalies is consistently negative, the strength of the AIR-Niño-3 index relationship undergoes large fluctuations. For example, the correlation between JJ AIR anomalies and the Niño-3 index is relatively weak around the 1950 s but approaches -0.8 around the 1890s. Prior to the 1970s, the sliding correlation curves do not fluctuate coherently, whereas around the 1970s the correlation curves begin fluctuating more coherently. The relationship between Niño-3 and AIR anomalies for all subseasons begins to weaken in near unison around the 1970s, but the extent of the weakening varies. The $\mathrm{JJ}$ subseason is associated 
(a)

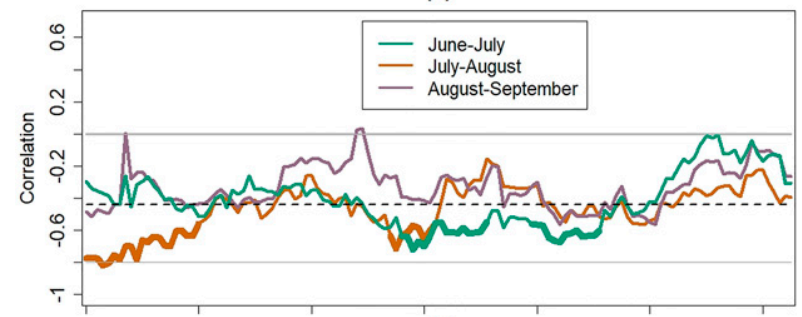

(b)

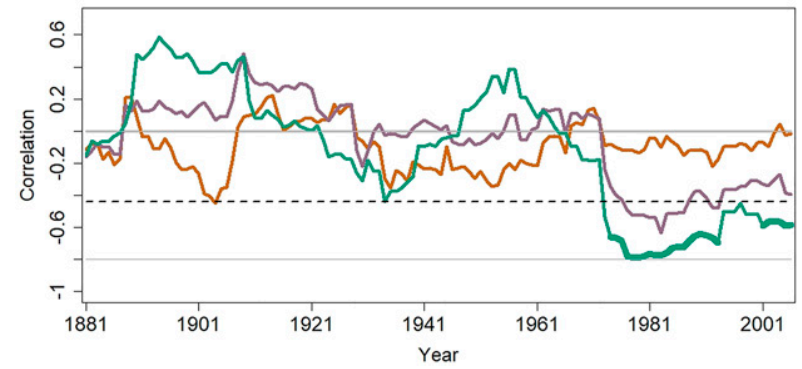

FIG. 2. (a) 20-yr sliding correlation between the Niño-3 index and time series for JJ, JA, and AS AIR rainfall anomalies. (b) As in (a), but with the trans-Niño-3 index. Dashed line represents the critical level of the pointwise test applied at the 5\% significance level, and the thickened lines indicate those correlation coefficients that are $5 \%$ arcwise significant.

with the least weakening, whereas the AS subseason is associated with the greatest weakening. These findings suggest that a similar mechanism is responsible for the degrading AIRENSO relationship in all subseasons, but the mechanism is more influential during the late monsoon than in the early monsoon season.

The weakening is also found when correlating AIR anomalies with the Niño-1+2 (Fig. 3), with the weakening Niño-1+2 AIR relationship being more pronounced. As a result, the correlation between the Niño-1+2 index and AIR anomalies for the 1979-2016 period is much weaker than the correlation between them for the 1871-2016 period (Table 1). The propensity for greater weakening in the late monsoon season is seen in Fig. 3 but is not found for the Niño-3.4 or Niño-4 index (not shown). Not surprisingly, the AS AIR relationships with the Niño-3.4 and Niño-4 indices for the 1979-2016 period are not much different than those for the 1871-2016 period (Table 1).

According to the 20-yr sliding nonlinearity indices shown in Fig. 4, the Niño-3-AIR relationship is mainly linear throughout the study period so that the fluctuations shown in Fig. 2a are likely unrelated to the validity of the linearity assumption so that additional analyses are needed to identify other sources of the variations.

\section{b. Partial correlation analysis}

The partial correlation coefficient between AIR anomalies and SSTA computed while controlling for the Niño-3 index reveals the SST patterns influencing the Niño-3-AIR relationship shown in Fig. 2a. As shown in Fig. 5, there are only a few small

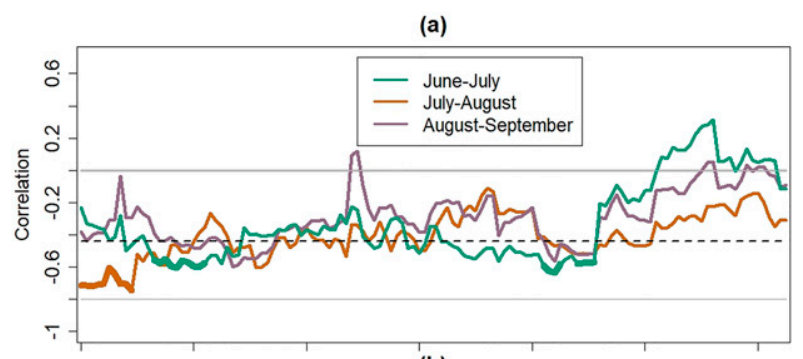

(b)

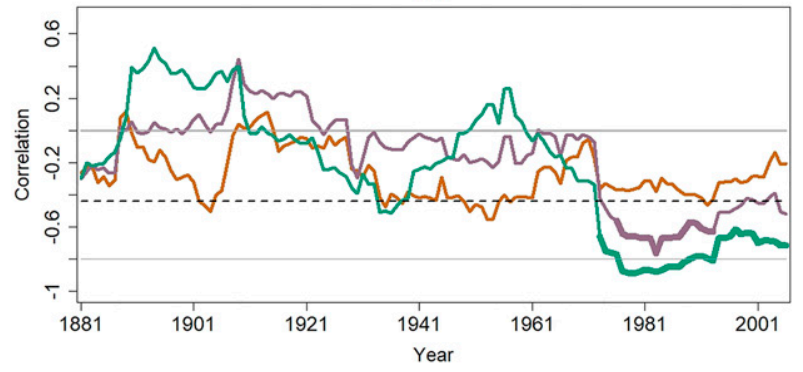

FIG. 3. (a) 20-yr sliding correlation between the Niño-1+2 index and time series for JJ, JA, and AS AIR rainfall anomalies. (b) As in (a), but between the trans-Niño-3 index and AIR residuals calculated using the Niño- $1+2$ index as a predictor. Dashed line represents the critical level of the pointwise test applied at the $5 \%$ significance level, and the thickened lines indicate those correlation coefficients that are 5\% arcwise significant.

regions of statistically significant partial correlation coefficients for the JJ subseason. For the JA and AS subseasons, statistically significant negative partial correlation coefficients are seen spanning the western side of the Niño-3 region (dashed box) and positive partial correlation coefficients are seen extending from the eastern side of the Niño-3 region to the west coast of South America. These results suggest that the relationship between AIR anomalies and the Niño-3 index during the mid- to late monsoon season is influenced by the SSTA gradient across the Niño-3 region such that negative AIR anomalies (droughts) are

TABLE 1. Correlation between climate indices and all-India rainfall. Boldface entries indicate $5 \%$ statistical significance.

\begin{tabular}{|c|c|c|c|c|c|c|}
\hline & JJA & JAS & $\mathrm{JJ}$ & JA & AS & FULL \\
\hline \multicolumn{7}{|c|}{ 1979-2016 } \\
\hline Trans-Niño-3 & -0.14 & -0.59 & 0.08 & -0.37 & -0.71 & -0.43 \\
\hline Niño-3 & -0.39 & -0.37 & -0.42 & -0.34 & -0.28 & -0.37 \\
\hline Niño-3.4 & -0.38 & -0.50 & -0.39 & -0.40 & -0.42 & -0.50 \\
\hline Niño-1+2 & -0.26 & -0.10 & -0.33 & -0.15 & -0.01 & -0.1 \\
\hline Niño-4 & -0.29 & -0.46 & -0.27 & -0.31 & -0.47 & -0.46 \\
\hline Trans-Niño & 0.07 & -0.25 & 0.19 & -0.06 & -0.38 & -0.14 \\
\hline \multicolumn{7}{|c|}{ 1871-2016 } \\
\hline Trans-Niño-3 & -0.08 & -0.25 & 0.02 & -0.11 & -0.28 & -0.23 \\
\hline Niño-3 & -0.50 & -0.47 & -0.50 & -0.38 & -0.43 & -0.56 \\
\hline Niño-3.4 & -0.48 & -0.49 & -0.48 & -0.36 & -0.46 & -0.58 \\
\hline Niño-1+2 & -0.40 & -0.36 & -0.41 & -0.30 & -0.32 & -0.42 \\
\hline Niño-4 & -0.38 & -0.40 & -0.40 & -0.24 & -0.40 & -0.49 \\
\hline Trans-Niño & 0.11 & 0.01 & 0.12 & 0.11 & -0.05 & 0.01 \\
\hline
\end{tabular}




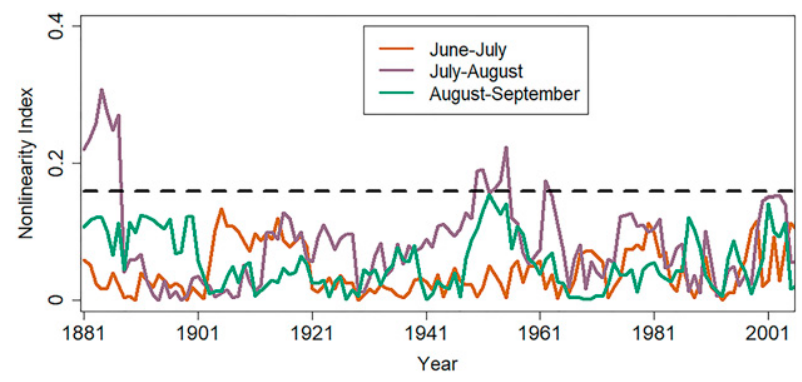

FIG. 4. 20-yr sliding time series of the (a) JJ, (b) JA, and (c) AS nonlinearity indices. Dashed lines represent the $5 \%$ significance bound.

favored when SSTA are positive across the central equatorial Pacific and negative across the eastern equatorial Pacific, a pattern consistent with a central Pacific El Niño event.

\section{c. The trans-Niño-3 index}

Based on the results shown in Fig. 5, we created a transNiño-3 (TN3) index that measures the strength of the SSTA gradient across the Niño-3 region. The index was constructed by first locating the point with the most negative partial correlation coefficient $(r=-0.71$; cross sign in Fig. 5c) and the point with the most positive partial correlation coefficient $(r=$ 0.66; plus sign in Fig. 5c). The SSTA at the two points were then extracted and normalized by their respective 1871-2016

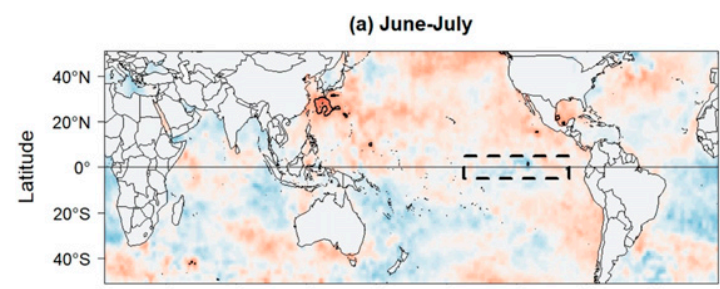

(b) July-August
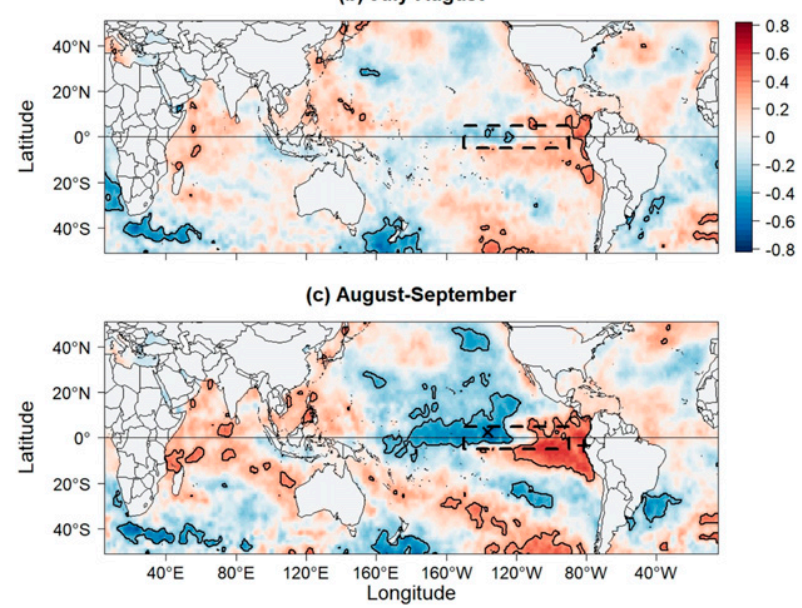

FIG. 5. Partial correlation between AIR anomalies and SSTAs for the (a) JJ, (b) JA, and (c) AS subseasons when controlling for the Niño-3 index. Time period is 1979-2016 and contours enclose regions of $5 \%$ statistical significance.
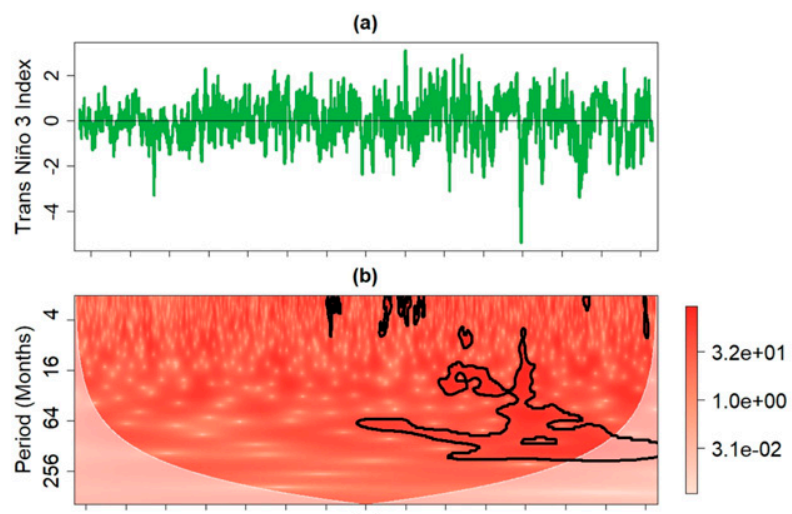

(c)

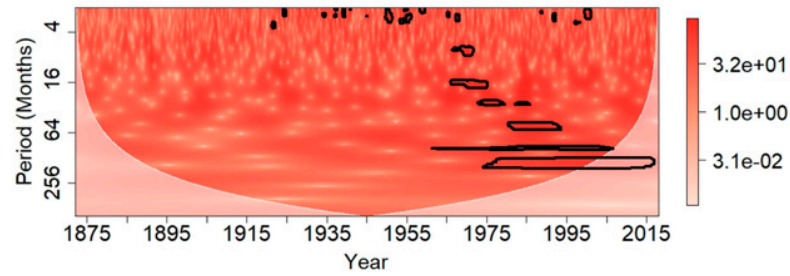

FIG. 6. The trans-Niño-3 index and its corresponding wavelet power spectrum after the application of the cumulative (b) areawise and (c) arcwise tests. Contours enclose regions of 5\% statistical significance, and the light shaded region represents the cone of influence.

standard deviations. The TN3 index was then defined as the normalized SSTA at the western grid point minus the normalized SSTA at the eastern grid point so that positive TN3 indices correspond to CP El Niño events in which normalized SSTA across the western Niño-3 region are greater than those across the eastern equatorial Pacific.

The time series of the TN3 index and its corresponding wavelet power spectrum are shown in Fig. 6. As shown in Fig. 6a, the strongest TN3 events have occurred in recent decades, with the most intense of all such events occurring around 1985. An inspection of Fig. 6a also reveals that the variance of the TN3 index has been increasing, with this increase in variance clearly seen in the wavelet power spectra shown in Figs. $6 \mathrm{~b}$ and $6 \mathrm{c}$. Around the 1940 s, there is an enhancement of wavelet power in the 16-128-month period band, with the wavelet power emerging as statistically significant. The wavelet power spectrum shown in Fig. 6c suggests that the TN3 time series contains oscillations with periods around 64 and 128 months.

Although the TN3 index is like the trans-Niño index defined by Trenberth and Stepaniak (2001), it is not perfectly correlated with it during the monsoon season (Fig. 7). The correlation between TN 3 and TNI range from 0.77 in the monsoon season to 0.94 during the boreal spring. The Niño-3 index is nearly orthogonal to the TN3 index during the monsoon season, highlighting the ability of the partial correlation method to extract orthogonal SST modes. However, the relationship is weak and negative during the boreal Spring and weak and positive during the boreal winter.

Despite the strong correlation during the monsoon season, the spatial patterns associated with the TN3 and TNI patterns 


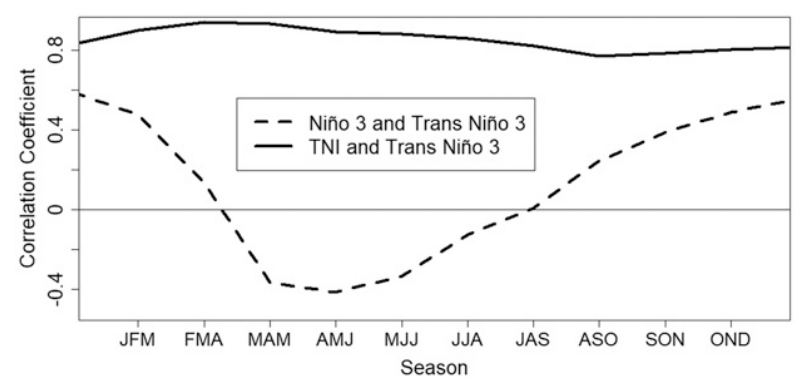

FIG. 7. Correlation between the trans-Niño-3 index and two common ENSO metrics.

display significant differences. For example, for the AS subseason, TN3 is weakly correlated with SSTA across the eastern equatorial Pacific, whereas the TNI is well correlated with SSTA across much of the Niño-3 region (Fig. 8). Furthermore, the TNI is less correlated with SSTA along the east coast of China and around Australia than the TN3 index. Finally, the TNI is positively correlated with SSTA across a relatively small region west of the Niño-3 domain. In contrast, the TN3 index is positively correlated with SSTA across a region extending from the western Pacific to western portions of the Niño-3 domain. Overall, the TNI represents an SST pattern whose SST dipole is shifted westward relative to that of the TN3 pattern. That is, the TNI represents the gradient across the Niño-3.4 region (Trenberth and Stepaniak 2001), whereas the TN3 pattern is the gradient across the Niño- 3 region. Thus, the TN3 index is needed to distinguish these slightly different SST patterns.

\section{d. Climate index relationships with AIR anomalies and residuals}

The relationships between AIR anomalies and various ENSO metrics are shown in Table 1. For the AS subseason, the trans-Niño-3 index is more strongly correlated $(r=-0.71)$ with

(a) TN3 and SST Anomalies

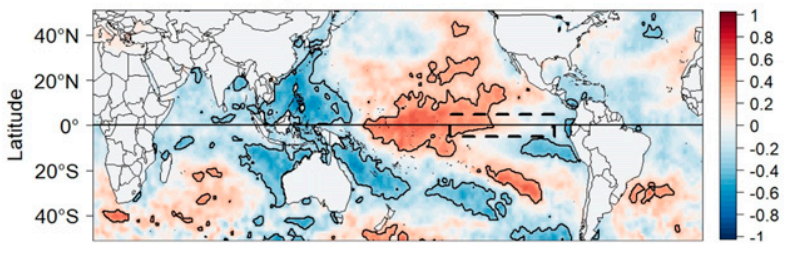

(b) TNI and SST Anomalies

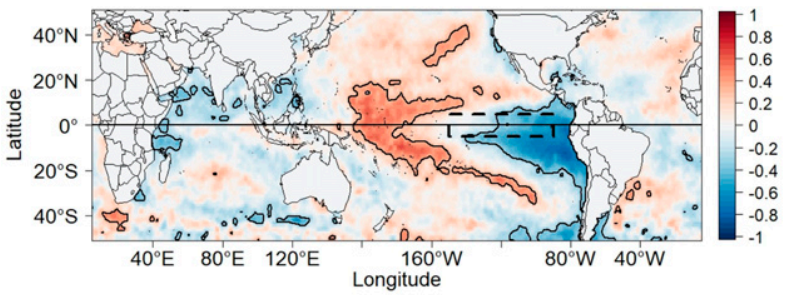

FIG. 8. Pearson correlation between the (a) TN3 index and SSTAs and (b) between TNI and SSTAs for the AS subseason. Time period is 1979-2016 and contours enclose regions of 5\% statistical significance.
TABLE 2. Correlation between climate indices and Niño-3 AIR residuals for the 1979-2016 period. Boldface entries indicate 5\% statistical significance.

\begin{tabular}{lcccccc}
\hline & JJA & JAS & JJ & JA & AS & Full \\
\hline Trans-Niño-3 & -0.14 & $\mathbf{- 0 . 5 9}$ & -0.02 & $\mathbf{- 0 . 4 2}$ & $\mathbf{- 0 . 7 0}$ & $\mathbf{- 0 . 4 9}$ \\
Trans-Niño & -0.10 & $\mathbf{- 0 . 4 2}$ & -0.1 & -0.22 & $\mathbf{- 0 . 4 9}$ & $\mathbf{- 0 . 4 2}$ \\
\hline
\end{tabular}

AIR anomalies than any other ENSO metric during the 19792016 period, with the index explaining $50 \%$ of AIR anomaly variability. However, the TN3 index correlation with AIR anomalies is weaker for the JJ, JA, and JJA seasons, with the JA correlation being comparable to that of many other ENSO metrics. These results indicate that the TN3 pattern becomes increasingly more influential as the summer monsoon season progresses. This strengthening relationship from the early to late monsoon season results in only a moderately strong JuneSeptember (full) AIR-TN3 index correlation, though the JAS relationship is still stronger than any other ENSO metric. The correlation between AIR anomalies and the TNI is weak for all subseasons.

Despite the weak correlation between the TNI and AIR anomalies, AIR residuals are moderately correlated with the TNI during the JAS and AS subseasons and the full monsoon season (Table 2). However, these relationships are weaker than the relationship between the TN3 index and AIR residuals, especially for the AS subseason. This result highlights the benefit of using the continuum framework for extracting optimal patterns because the TNI and TN3 index both measure the intensity of central Pacific El Niño events, but the continuum approach has determined that the TN3 pattern is the central Pacific El Niño flavor within the ENSO continuum most strongly related to AIR residuals. The TN3 index relationship with AIR residuals for the other subseasons is weak, but the sign of the relationship is consistent throughout the entire monsoon season. The negative correlation implies that the observed precipitation tends to be lower than the AIR anomaly predicted by the Niño-3 index when SSTA are greater in the central equatorial Pacific than in the eastern equatorial Pacific (i.e., when the TN3 index is positive). A situation in which this SSTA pattern would occur is during central Pacific El Niño events, so that our results support conclusions that changes in the ENSO-India rainfall relationship are related to the occurrence of ENSO flavors (Kumar et al. 2006; Fan et al. 2017). The strong correlation between AIR residuals and the TN3 index also means that time periods when the TN3 pattern is intense are also time periods when the Niño-3-AIR relationship is weak (section 4e), because large TN3 indices contribute to spread around a fitted linear Niño-3 index prediction curve, weakening the Pearson correlation coefficient. Comparing TN3 to TNI with respect to Niño-3-AIR residuals, we see that TN3 has stronger correlations for the full monsoon season and for subseasons that include the late monsoon period (Table 2). This result reflects how the TN3 was defined with respect to deviations from the ENSO signal, whereas the TNI was derived independently of the Indian monsoon. Although the TN3 and TNI patterns are similar (Fig. 8), the slight 


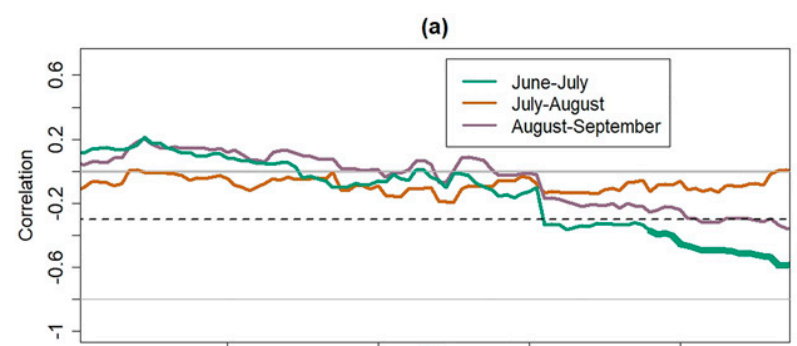

(b)

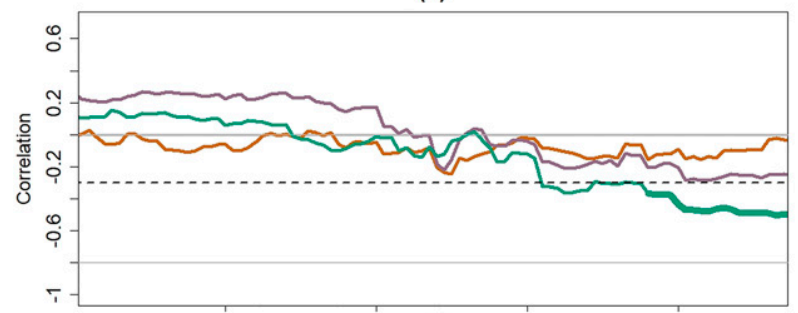

(c)

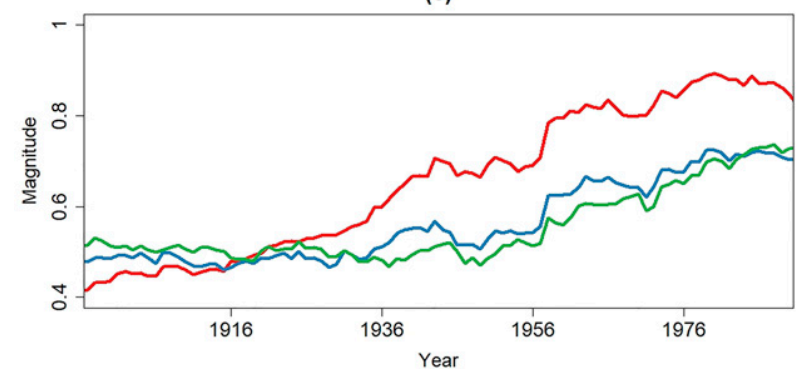

FIG. 9. 50-yr sliding correlation (a) between the trans-Niño-3 index and AIR residuals and (b) between the TNI and AIR residuals for three monsoon subseasons. (c) 50-yr sliding mean magnitude (absolute value) time series of the trans-Niño-3 index.

differences are associated with large differences in the correlation strengths, highlighting the importance of the TN3 index to the understanding of the Indian monsoon.

\section{e. Time evolution of the trans-Niño-3-index-AIR relationship}

The 20-yr sliding correlation between AIR anomalies and the TN3 index highlights the time evolution of the TN3 relationship with AIR anomalies. As shown in Fig. 2b, the strength of the AIR-TN3 index relationship has been generally increasing since the 1970 s for the JA and AS subseasons, coinciding with the weakening AIR-Niño-3 relationship (Fig. 2a). The AS AIR-TN3 index relationship is strongest around the late 1970s and early 1980s when the correlation coefficient reaches -0.84 , which implies that the index can explain up to $71 \%$ of AS AIR anomaly variability. The correlation slightly weakens after the late 1970 s, but the relationship remains strong to the end of the study period. In contrast, around the early 1900s the correlation is weakly positive, indicating that the relationship is highly nonstationary. Because the Niño-3 and TN3 indices are nearly orthogonal (Fig. 7) during the summer monsoon season, the weakening Niño-3-AIR relationship means that there is a strengthening TN3-AIR relationship. In fact, the orthogonality of the patterns partially

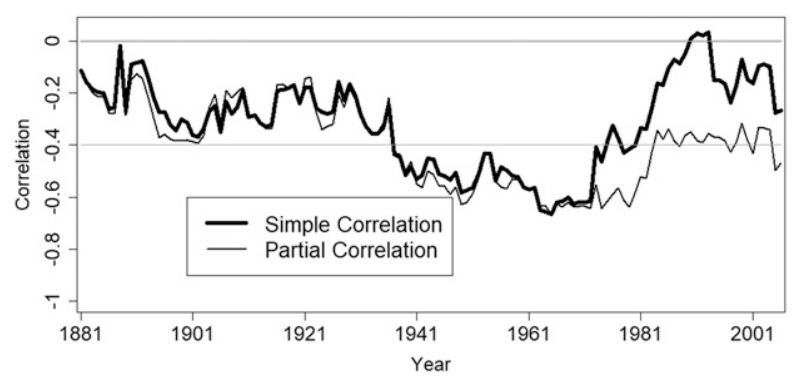

FIG. 10. Simple correlation and partial correlation between the AS Niño-3 and AIR anomalies, where the partial correlation coefficients were calculated when controlling for the AS TNI.

explains why the Niño-3-AIR relationships for all subseasons weaken after the 1970s in near unison but to varying extents. The reason is that the TN3 pattern contributes to the spread around the ENSO signal in all-subseason, but the AS Niño-3AIR relationship weakens more than the Niño-3-AIR relationship for the JJ and JA subseasons because the TN3 pattern is more strongly influencing the spread later in the monsoon season.

To better understand the impact of the TN3 pattern on the Niño-3-AIR relationship, the 50-yr sliding correlation between the TN3 index and Niño-3-AIR residuals were computed for each subseason. The residuals were calculated from a linear regression model in which the Niño-3 index was the predictor. Figure 9a clearly shows how the influence of the TN3 pattern on the deviations from the Niño-3 signal has been strengthening since around the 1940s. For all subseasons, the relationship between AIR residuals and TN3 index is rather stable and weak until around 1956, though the trend toward more negative correlations begins around the 1930s. After 1956, the relationship begins to strengthen rapidly, with the strengthening influence being most pronounced for the AS season and least pronounced for the JJ subseason. A comparison of Figs. 2a and 9a reveals an inverse relationship between the extent of weakening of the Niño-3-AIR relationship and the extent of strengthening of the AIR residual relationship with the TN3 index. These results imply that the TN3 pattern can explain not only the weakening Niño-3-AIR relationships shown in Fig. 2a, but also the differences in the sliding correlation curves for the three subseasons after the 1960s.

Like for the TN3 pattern, the TNI pattern also has an increasing influence on the AS Niño-3-AIR relationships (Fig. 9b), but it is less pronounced than the influence of the TN3 pattern. Because the TNI and Niño-3 index are correlated, the Niño-3 the impact of the TNI pattern on the Niño-3AIR relationship can be visualized by computing the sliding correlation and partial correlation (controlling for TNI) with AIR (Fig. 10). The simple and partial correlation with AS AIR are nearly equal prior to the 1960 s, reflecting the weak influence of the TNI pattern. However, after the 1960s the two correlation time series diverge, and the partial correlation is stronger than the simple correlation. This result implies that the Niño-3-AIR relationship would be stronger in the absence of SSTA gradients across the equatorial Pacific. Or, 
equivalently, that recent weakening of the Niño-3-AIR relationship is associated with a tendency toward CP flavored El Niño events.

The strengthening influence of the TN3 pattern appears to track closely with the intensification of the TN3 pattern (Fig. 9c), especially for the JA and AS subseasons. The intensity of the TN3 pattern is relatively stable until around the 1930s. During this time period, the TN3-AIR relationship is quite weak and opposite to the TN3-AIR relationship in recent decades. However, once the TN3 pattern begins to intensify after the 1930s, the influence of the pattern strengthens considerably. Indeed, the peak in the correlation coefficient occurring around the 1980s (Fig. 2b) coincides with the most intense TN3 event on record (Fig. 6a). These results indicate that impact of the TN3 pattern on AIR during the mid- to late monsoon season is related to the intensity of the pattern.

This result reflects how the Niño-3 index cannot adequately capture the ENSO flavors most relevant to the mid- to late Indian summer monsoon. For example, a near-zero Niño-3 index could be associated with both a CP El Niño and a pattern inverse to that pattern, but these patterns are associated with different Indian summer responses according to Figs. $2 \mathrm{~b}$ and 5 and previous work (Fan et al. 2017) As the SSTA gradient across the equatorial Pacific intensifies, this deficiency of the Niño-3 index manifests itself more clearly (Fig. 9a). A similar situation occurs for the Niño-1+2 index because a droughtinducing canonical ENSO and a monsoon surplus promoting negative TN3 pattern (Table 1) could be associated with similarly valued Niño- $1+2$ indices. The competing influence of these patterns would weaken the Niño-1+2-AIR relationship because now the same Niño- $1+2$ index would be associated with different AIR anomalies, contributing to deviations from a one-to-one linear relationship (Fig. 3b) and reversals of the Niño-1+2-AIR relationship (Fig. 3a). This mechanism seems to be influencing the Niño-1+2-AIR relationship very strongly because the correlation between the TN3 index and AIR residuals calculated with Niño-1+2 as a predictor approaches 0.9 during the AS subseason around the 1980s (Fig. 3b).

\section{f. Independent TN3 and TNI forecasts}

To better highlight how the TN3 index could be a useful AIR predictor, we compared the out-of-sample forecast skill of the TN3 index and the TNI. To assess the out-of-sample skill, we constructed linear regression models based on data for the 1979-2006 period then produced independent forecasts using data for the 2007-16 period. The models were made for the AS season because the AIR-TN3 relationship is strong. The forecast skill was first quantified by correlating model residuals with the observed AIR. Second, the normalized root-mean square error (NRMSE) was also computed, where normalization was achieved by dividing the raw root-mean square error by the standard deviation of the observed AIR. The results were visualized using percent errors, which were calculated by multiplying the model residuals (i.e., observed minus predicted) by 100 and dividing the result by the observed precipitation.

As shown in Fig. 11, the performance of the models depends on the chosen predictor. The TN3-based predictions for the

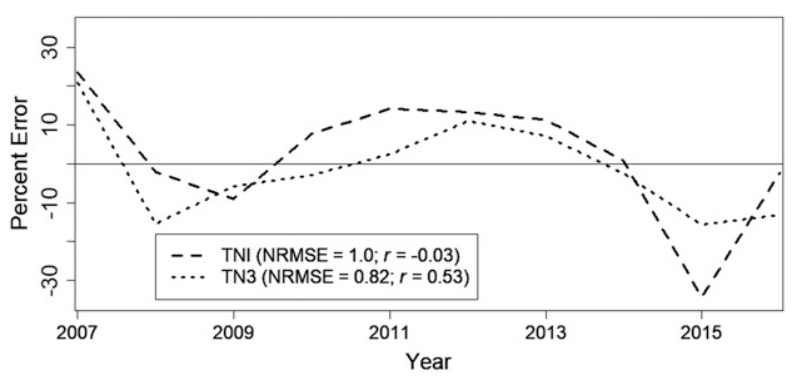

FIG. 11. Percent error associated with the TN3 and TNI AS AIR predictions.

out-the-sample period appear to track more closely with the observed AIR than the TNI-based predictions. For example, the TN3 index better predicts 2015 AS precipitation than the TNI index. Other years with better TN3-based predictions are the 2010 and 2011 AS seasons.

The better performance of the TN3 index is reflected in both the NRMSE and correlation skill (Fig. 11). The TN3 is seen to produce skillful independent forecasts, with the NRMSE being less than one and the correlation skill being positive. When using the TNI as a predictor, the NRMSE is close to one, indicating that the out-of-sample skill is low. In fact, the TNI predicts AIR to be opposite to the observed AIR, as indicated by the negative correlation skill. According to these results, a forecaster using the TN3 index would produce better AIR forecasts than a forecaster using the TNI. These results support the idea that selecting the most relevant ENSO flavor among a continuum of patterns is useful in constructing statistical models.

\section{g. TN3 relationship with atmospheric circulation parameters}

Physically, the differences in the Niño-3-AIR and TN3AIR relationships reflect the distinct atmospheric patterns associated with them. As shown in Fig. 12, the TN3 index is negatively correlated with 500-hPa omega anomalies across the central equatorial Pacific, which is expected because positive SSTA in this region associated with positive TN3 phases (Fig. 8) should enhance convection. As a result, positive TN3 phases are associated with negative $200-\mathrm{hPa}$ VP anomalies and 200-hPa large-scale divergence across the central equatorial Pacific. The Niño-3 index is also negatively correlated with 500$\mathrm{hPa}$ omega anomalies but over a larger region extending from the central equatorial Pacific to the eastern equatorial Pacific. The strong negative correlations are accompanied by strong positive correlations over the Maritime Continent, with this negative-positive correlation dipole representing the differential response of the Walker circulation to cool and warm Niño-3 events. The correlation between the Niño-3 index and 200-hPa VP anomalies further highlights how positive Niño-3 phases are associated with large-scale divergence over the equatorial Pacific and convergence over the Maritime Continent and surrounding areas. In contrast to the Niño-3 index, the TN3 index is only weakly correlated with $500-\mathrm{hPa}$ omega anomalies over the Maritime Continent and only positively correlated with 200-hPa VP anomalies over the Indian 
(a) TN3 with 200-hPa VP and 500-hPa Omega Anomalies

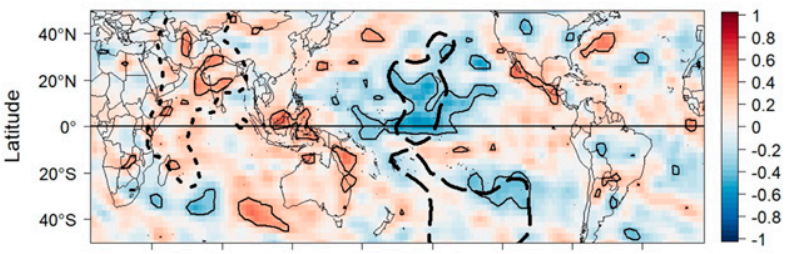

(b) Niño 3 with 200-hPa VP and 500-hPa Omega Anomalies

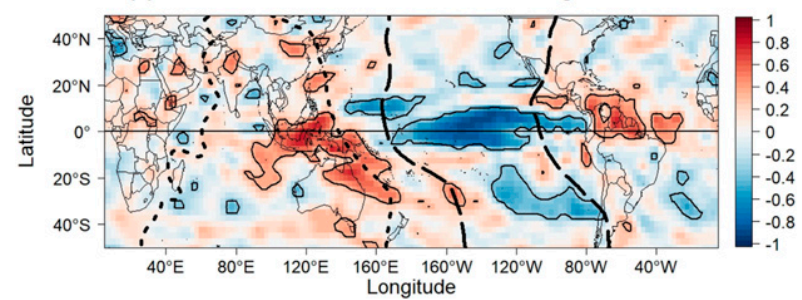

FIG. 12. (a) Pearson correlation between the TN3 index and AS anomalies for 200-hPa VP and 500-hPa omega anomalies. (b) As in (a), but for the Niño-3 index. Time period is 1979-2016 and contours enclose regions of $5 \%$ statistical significance. Thick longdashed (short-dashed) contours enclose the region where the correlation between a climate index and $200-\mathrm{hPa}$ VP falls below (exceeds) -0.5 (0.5).

subcontinent and a region extending from Africa to India. These results indicate that the subsidence region associated with positive TN3 phases is concentrated around India. It is worth noting that the TN3 index is correlated with $500-\mathrm{hPa}$ omega anomalies over a larger portion of India than the Niño-3 index, which is consistent with prior work showing how $\mathrm{CP} \mathrm{El}$ Niño events are more effective at producing drought-inducing subsidence over India than EP El Niño events.

A correlation analysis with SLP anomalies further highlights the difference in circulation patterns associated with the TN3 and Niño-3 indices (Fig. 13). The negative correlation seen between the Niño-3 index and SLP anomalies across the eastern equatorial Pacific reflects changes in the eastern branch of the Walker Circulation in response to Niño-3 warm events because anomalous rising motion (negative $500-\mathrm{hPa}$ omega anomalies) induces anomalously low surface pressure. Similarly, anomalous sinking motion (positive 500-hPa omega anomalies) during warm Niño-3 events are associated with increases in surface pressure (positive SLP anomalies), which is why the Niño-3 index is positively correlated with SLP anomalies across the Maritime Continent. The TN3 index is also associated with a negative-positive correlation dipole, but the dipole is shifted westward relative to the one associated with the Niño-3 index, though the Niño-3 index is correlated with SLP anomalies across India. We interpret this relative displacement as a shift in the Walker Circulation cell such that the rising branch is located over the central equatorial Pacific and the descending branch is located around India during positive TN3 phases. Thus, our results support findings that CP El Niño events are associated with shifts in the Walker circulation and favor drought-producing subsidence over India. (a) TN3 and SLP Anomalies

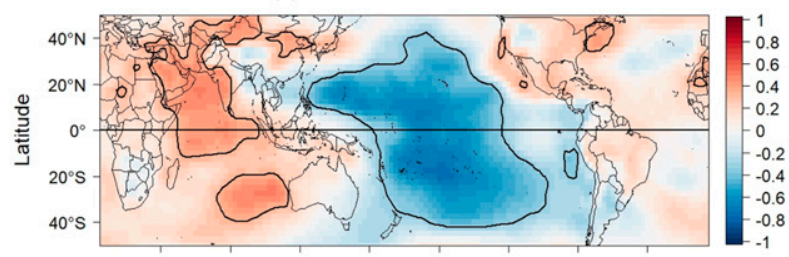

(b) Niño 3 and SLP Anomalies

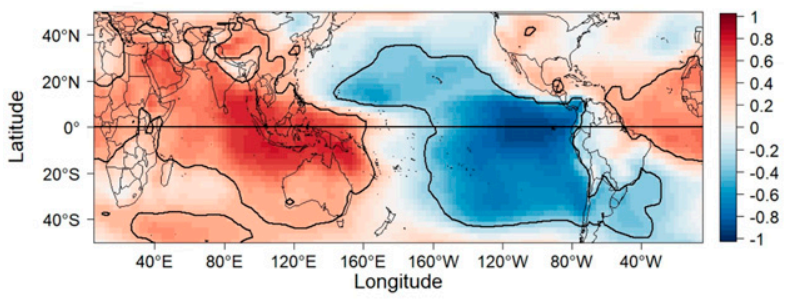

FIG. 13. Pearson correlation (a) between the TN3 index and SLP anomalies and (b) between the Niño-3 index and SLP anomalies for the AS subseason. Time period is 1979-2016 and contours enclose regions of $5 \%$ statistical significance.

\section{Discussion}

Using one-point partial correlation maps, we identified an SSTA pattern among a continuum of patterns that optimally explains AIR anomaly variability for the late (JuneSeptember) monsoon subseason. The identified pattern was called the trans-Niño-3 (TN3) pattern because the pattern represented the SSTA gradient across the Niño-3 region. The strength and evolution of the pattern was measured using a simple index called the TN3 index, which was shown to be strongly correlated with AIR anomalies during the late summer monsoon season, with the relationship strengthening since the 1940s.

Not only was the index found to be strongly correlated with AIR anomalies, but also with AIR residuals associated with a linear regression model in which the Niño-3 and Niño- $1+2$ indices were predictors. These results provide compelling evidence that changes in the ENSO-AIR relationship are not random during the late mid- to late monsoon season. According to Yun and Timmermann, (2018), Indian summer rainfall is the superposition of an ENSO signal and noise, but our results do not support this conclusion for the mid- to late monsoon season, especially after the 1970s. Instead, fluctuations around the ENSO signal, as measured using AIR residuals, were found to be strongly related to the intensity of the TN3 pattern. Our results, however, do support findings from previous work showing how the Indian monsoon differentially responds to $\mathrm{CP}$ El Niño and EP El Niño events (Kumar et al. 2006; Fan et al. 2017). According to the findings from this study and previous work, incorporating information about ENSO flavors into Indian monsoon forecasts should improve forecast skill.

The influence of the TN3 pattern has been increasing since the 1940s, with the influence being particularly strong during the late monsoon season. The intensifying influence was found to track closely with increases in the intensity of the TN3 
pattern. After the 1940s, the intensity of the pattern greatly increased, which coincided with the rapid strengthening of its influence. These results seem to suggest that a key to understanding why the TN3 pattern has emerged as a leading mode governing AIR variability rests in a firmer understanding of why the pattern has been intensifying.

One caveat to our findings is that there is uncertainty in the HADD SST dataset so that the precise behavior of the TN3 pattern is uncertain, especially prior to the 1950s. Nevertheless, three reasons give us confidence in our results. First, Niño indices calculated for the 1871-2018 period have the physically consistent negative correlation with AIR. Second, confidence in our results is derived from previous studies focusing on the physical mechanism behind recent increases in CP El Niño intensity and occurrence. As shown by Yeh et al., (2009), the occurrence of $\mathrm{CP}$ events could increase because of global warming and the flattening of the thermocline (Yeh et al. 2009). In a subsequent study, Lee and McPhaden, (2010) showed that the increasing intensity of CP El Niño events is the result of more intense El Niño events in recent decades that are generally related to more pronounced nonlinear ENSO behavior (An and Jin 2004) after the 1970s compared to previous time periods (An 2004). Thus, the general changes in TN3 pattern more likely reflect a physical change in the ENSO system than a change in the observing system. Third, to enhance our confidence, we calculated TN3 index using the Extended Reconstructed Sea Surface Temperature, version 4 (Huang et al. 2015) dataset and correlated the resulting time series with AIR anomalies. We found similar correlation strengths and sign changes to the ones reported in this study, giving us confidence that the results are not dataset specific. Although the uncertainty in the Extended Reconstructed Sea Surface Temperature, version 4, dataset after the 1950s is large enough to influence the detailed ranking of individual ENSO events (Huang et al. 2016), it is small enough that the general behavior of ENSO can be inferred so that the increased intensity of the TN3 pattern after the 1950s is unlikely an artifact of changes in the observing system.

Another limitation of our study is that the study did not include an in-depth analysis of the physical mechanisms linking the TN3 pattern to AIR. One reason for the TN3-AIR relationship could be the TN3 pattern's influence on sea level pressure (SLP) anomalies over the Arabian Sea. For most months, AIR is related to SLP anomalies across the Arabian Sea (not shown), which is physically consistent with how negative SLP anomalies or an anomalously cyclonic flow is associated with an onshore flow from the ocean. On the other hand, positive SLP anomalies are associated with an anomalous anticyclonic flow over terrestrial regions lacking moisture sources. As shown in Fig. 12, the region of large-scale subsidence associated with the TN3 pattern is located over the Arabian Sea, which means that the TN3 pattern should influence the SLP anomalies across the Arabian Sea (Fig. 12). According to this preliminary analysis, positive TN3 phases tend to be associated with anomalous anticyclonic flow, supporting the idea that positive TN3 phases are associated with droughts. However, these results are speculative, and additional observational and modeling studies are needed to better characterize the physical mechanism relating the $\mathrm{TN} 3$ pattern to AIR.
As noted by Schulte et al. (2020), ENSO nonlinearity could be related to changes in the ENSO-AIR relationship because different ENSO nonlinear modes contribute to different ENSO flavors. They noted, for example, some nonlinear Niño$1+2$ modes contribute to skewness and intensity of positive SSTA across the eastern equatorial Pacific, which means that strong negative TN3 patterns will be more likely to occur during time periods of enhanced Niño- $1+2$ nonlinearity. Thus, our findings support the conclusion that ENSO nonlinearity is related to the strength of the ENSO-Indian monsoon relationship.

Beyond offering a simple diagnostic tool, the TN3 index may have potential prognostic value. The prognostic value would depend on how well current dynamical seasonal forecasting models can predict the pattern with advanced lead times. According to a study by Zheng and Yu (2017), the forecast skill for central Pacific El Niño events is less than that of east Pacific El Niño events, with the spring predictability barrier for central Pacific El Niño events being stronger as well. Those findings imply that long-range AIR forecasts based on the TN3 pattern could be a challenging endeavor. However, determining how well central Pacific El Niño events can be predicted depends on the chosen index used to measure a central Pacific El Niño and the time of year so that further research is needed to assess how well models replicate and predict the TN3 pattern. Nevertheless, a wavelet power spectral analysis of the TN3 index identified statistically significant periodicities on decadal time scales, which implies that the TN3 pattern cycles between negative and positive phases with some regularity. Because the TN3 index is strongly correlated with AIR, this finding implies that AIR anomalies may too cycle between periods of negative and positive anomalies. The high autocorrelation (persistence) of the TN3 index (not shown) may afford additional prognostic capabilities. The high persistence means that the index could be used to predict AIR anomalies with advanced lead times, providing adequate preparation time for the potential negative impacts of monsoon failures.

Acknowledgments. This research has been supported by the NASA Applied Sciences Project (Grant NNX26AN38G).

Data availability statement. The Hadley Centre Global Sea Ice and Sea Surface Temperature data set (available at https:// www.esrl.noaa.gov/psd/gcos_wgsp/Timeseries/Data/nino34. long.data, last accessed 15 March 2019). The all-India rainfall data can be accessed through the Indian Institute of Tropical Meteorology website (https://www.tropmet.res.in/DataArchival51-Page, last accessed 15 March 2019). The Niño-1+2, Niño-3, Niño-3.4, and Niño-4 indices are available at https://www.esrl. noaa.gov/psd/gcos_wgsp/Timeseries/Data/nino34.long.data.

\section{APPENDIX}

\section{Performance of the Arcwise Test}

The ability of the arcwise test to control the number of false positive was evaluated using an experiment in which 1000 pairs of red noise process realizations with length 1752 were 
TABLE A1. Estimates of the expected portion of correlation coefficients deemed arcwise significant when the null hypothesis of red noise is true.

\begin{tabular}{lcccc}
\hline & \multicolumn{4}{c}{ Lag-1 autocorrelation coefficient } \\
\cline { 2 - 5 } Significance level & 0.1 & 0.3 & 0.5 & 0.7 \\
\hline 0.05 & 0.005 & 0.007 & 0.016 & 0.033 \\
0.1 & 0.008 & 0.010 & 0.028 & 0.040 \\
0.15 & 0.009 & 0.012 & 0.033 & 0.054 \\
\hline
\end{tabular}

generated. For each pair, the 240-point (i.e., 20-yr) sliding correlation was computed and the arcwise test was applied at the $5 \%$ significance level using the $0.01,0.05,0.1$, and 0.15 pointwise significance levels. Then, for each pair, the fraction of correlation coefficients that were deemed arcwise significant were computed. Averaging the computed 1000 fractions resulted in an estimate of the expected proportion of false positives when the null hypothesis of red noise is true.

In this study, lag-1 autocorrelation coefficients were less than 0.2 , so that the arcwise test applied at the $5 \%$ significance level was very stringent, with only 0.005 of correlation coefficients being falsely deemed as significant on average. Increasing the arcwise significance level made the test less stringent, but the stringency depended slightly on the input lag-1 autocorrelation coefficients (Table A1).

\section{REFERENCES}

An, S.-I., 2004: Interdecadal changes in the El Niño-La Niña symmetry. Geophys. Res. Lett., 31, L23210, https://doi.org/ 10.1029/2004GL021699.

— 2009: A review of interdecadal changes in the nonlinearity of the El Niño-Southern Oscillation. Theor. Appl. Climatol., 97, 29-40, https://doi.org/10.1007/s00704-008-0071-z.

— , and F.-F. Jin, 2004: Nonlinearity and asymmetry of ENSO. J. Climate, 17, 2399-2412, https://doi.org/10.1175/1520-0442(2004) 017<2399:NAAOE $>2.0 . \mathrm{CO} ; 2$.

—_, Y. G. Ham, J. S. Kug, F. F. Jin, and I. S. Kang, 2005: El NiñoLa Niña asymmetry in the Coupled Model Intercomparison Project simulations. J. Climate, 18, 2617-2627, https://doi.org/ 10.1175/JCLI3433.1.

Ashok, K., Z. Guan, and T. Yamagata 2001: Impact on the Indian Ocean dipole on the relationship between the Indian monsoon rainfall and ENSO. Geophys. Res. Lett., 28, 4499-4502, https:// doi.org/10.1029/2001GL013294.

,,-- N. H. Saji, and T. Yamagata, 2004: Individual and combined influences of ENSO and the Indian Ocean dipole on the Indian summer monsoon. J. Climate, 17, 3141-3155, https://doi.org/10.1175/1520-0442(2004)017<3141:IACIOE $>2$. $0 . \mathrm{CO} ; 2$.

—_, S. K. Behera, S. A. Rao, H. Weng, and T. Yamagata, 2007: El Niño Modoki and its possible teleconnection. J. Geophys. Res., 112, C11007, https://doi.org/10.1029/ 2006JC003798.

Cash, B. A., and Coauthors, 2017: Sampling variability and the changing ENSO-monsoon relationship. Climate Dyn., 48, 4071-4079, https://doi.org/10.1007/s00382-016-3320-3.

Chen, S. J., J. H. He, and Z. W. Wu, 2013: New ocean atmosphere coupling indices for El Niño (in Chinese). Chin. J. Atmos. Sci., 37, 815-828.
Chen, W., B. Dong, and R. Lu, 2010: Impact of the Atlantic Ocean on the multidecadal fluctuation of El Niño-Southern Oscillation-South Asian monsoon relationship in a coupled general circulation model. J. Geophys. Res., 115, D17109, https://doi.org/10.1029/2009JD013596.

Dommenget, D., and M. Latif, 2002: A cautionary note on the interpretation of EOFs. J. Climate, 15, 216-225, https://doi.org/ 10.1175/1520-0442(2002)015<0216:ACNOTI >2.0.CO;2.

Fan, F., X. Dong, X. Fang, F. Xue, F. Zheng, and J. Zhu, 2017: Revisiting the relationship between the south Asian summer monsoon drought and El Niño warming pattern. Atmos. Sci. Lett., 18, 175-182, https://doi.org/10.1002/asl.740.

Franzke, C., and S. B. Feldstein, 2005: The continuum and dynamics of Northern Hemisphere teleconnection patterns. J. Atmos. Sci., 62, 3250-3267, https://doi.org/10.1175/JAS3536.1.

Gershunov, A., N. Schneider, and T. Barnett, 2001: Low-frequency modulation of the ENSO-Indian monsoon rainfall relationship: Signal or noise? J. Climate, 14, 2486-2492, https://doi.org/ 10.1175/1520-0442(2001)014<2486:LFMOTE $>2.0$. CO;2.

Huang, B., and Coauthors, 2015: Extended Reconstructed Sea Surface Temperature version 4 (ERSST.v4). Part I: Upgrades and intercomparisons. J. Climate, 28, 911-930, https://doi.org/ 10.1175/JCLI-D-14-00006.1.

—, M. L'Heureux, Z. Z. Hu, and H. M. Zhang, 2016: Ranking the strongest ENSO events while incorporating SST uncertainty. Geophys. Res. Lett., 43, 9165-9172, https://doi.org/10.1002/ 2016 GL070888.

Johnson, N. C., 2013: How many ENSO flavors can we distinguish? J. Climate, 26, 4816-4827, https://doi.org/10.1175/JCLI-D-1200649.1.

— , and S. B. Feldstein, 2010: The continuum of North Pacific sea level pressure patterns: Intraseasonal, interannual, and interdecadal variability. J. Climate, 23, 851-867, https://doi.org/ 10.1175/2009JCLI3099.1.

Kalnay, E., and Coauthors, 1996: The NCEP/NCAR 40-Year Reanalysis Project. Bull. Amer. Meteor. Soc., 77, 437-471, https://doi.org/10.1175/ 1520-0477(1996)077<0437:TNYRP > 2.0.CO;2.

Kao, H.-Y., and J.-Y. Yu, 2009: Contrasting eastern-Pacific and central-Pacific types of ENSO. J. Climate, 22, 615-632, https:// doi.org/10.1175/2008JCLI2309.1.

Kestin, T. A., D. J. Karoly, J.-I. Yano, and N. A. Rayner, 1998: Time-frequency variability of ENSO and stochastic simulations. J. Climate, 11, 2258-2272, https://doi.org/10.1175/15200442(1998)011<2258:TFVOEA > 2.0.CO;2.

Krishnamurthy, V., and B. N. Goswami, 2000: Indian monsoon-ENSO relationship on interdecadal timescale. J. Climate, 13, 579-595, https:// doi.org/10.1175/1520-0442(2000)013<0579:IMEROI>2.0.CO;2.

Kucharski, F., A. Bracco, J. H. Yoo, and F. Molteni, 2007: Lowfrequency variability of the Indian monsoon-ENSO relationship and the tropical Atlantic: The "weakening" of the 1980s and 1990s. J. Climate, 20, 4255-4266, https://doi.org/ 10.1175/JCLI4254.1.

,,--- A. M. Tompkins, L. Feudale, P. Ruti, and A. Dell'Aquila, 2009: A Gill-Matsuno-type mechanism explains the tropical Atlantic influence on African and Indian monsoon rainfall. Quart. J. Roy. Meteor. Soc., 135, 569-579, https://doi.org/10.1002/qj.406.

Kug, J.-S., F.-F. Jin, and S.-I. An, 2009: Two types of El Niño events: Cold tongue El Niño and warm pool El Niño. J. Climate, 22, 1499-1515, https://doi.org/10.1175/2008JCLI2624.1.

Kumar, K., B. Rajagopalan, and M. A. Cane, 1999: On the weakening relationship between the Indian monsoon and ENSO. Science, 284, 2156-2159, https://doi.org/10.1126/science.284.5423.2156. 
M. Hoerling, G. Bates, and M. Cane, 2006: Unraveling the mystery of Indian monsoon failure during El Niño. Science, 314, 115-119, https://doi.org/10.1126/science.1131152.

Lee, T., and M. J. McPhaden, 2010: Increasing intensity of El Niño in the central-equatorial Pacific. Geophys. Res. Lett., 37, L14603, https://doi.org/10.1029/2010GL044007.

Lu, R., B. Dong, and H. Ding, 2006: Impact of the Atlantic Multidecadal Oscillation on the Asian summer monsoon. Geophys. Res. Lett., 33, L24701, https://doi.org/10.1029/2006GL027655.

Parthasarathy, B., A. A. Munot, and D. R. Kothawale, 1994: All India monthly and seasonal rainfall series, 1871-1993. Theor. Appl. Climatol., 49, 217-224, https://doi.org/10.1007/BF00867461.

Rayner, N. A., P. Brohan, D. E. Parker, C. K. Folland, J. J. Kennedy, M. Vanicek, T. Ansell, and S. F. B. Tett, 2006: Improved analyses of changes and uncertainties in sea surface temperature measured in situ since the mid-nineteenth century: The HadSST2 data set. J. Climate, 19, 446-469, https:// doi.org/10.1175/JCLI3637.1.

Ren, H.-L., and F.-F. Jin, 2011: Niño indices for two types of ENSO. Geophys. Res. Lett., 38, L04704, https://doi.org/ 10.1029/2010GL046031.

Santoso, A., S. McGregor, F.-F. Jin, W. Cai, M. H. England, S.-I. An, M. J. McPhaden, and E. Guilyardi, 2013: Late-twentiethcentury emergence of the El Niño propagation asymmetry and future projections. Nature, 504, 126-130, https://doi.org/ 10.1038/nature12683.

Schulte, J. A., 2016: Cumulative areawise testing in wavelet analysis and its application to geophysical time series. Nonlinear Processes Geophys., 23, 45-57, https://doi.org/10.5194/npg-2345-2016.

_- 2019: Statistical hypothesis testing in wavelet analysis: Theoretical developments and applications to Indian rainfall. Nonlinear Processes Geophys., 26, 91-108, https://doi.org/ 10.5194/npg-26-91-2019.

- and S. Lee, 2019: Long Island Sound temperature variability and its associations with the ridge-trough dipole and tropical modes of sea surface temperature variability. Ocean Sci., 15, 161-178, https://doi.org/10.5194/os-15-161-2019.

_, R. G. Najjar, and S. Lee, 2017a: Salinity and streamflow variability in the mid-Atlantic region of the United States and its relationship with large-scale atmospheric circulation patterns. J. Hydrol., 550, 65-79, https://doi.org/10.1016/ j.jhydrol.2017.03.064.
— N. Georgas, V. Saba, and P. Howell, 2017b: Meteorological aspects of the Eastern North American pattern with impacts on long island sound salinity. J. Mar. Sci. Eng., 5, 26, https:// doi.org/10.3390/jmse5030026.

_ F. Policelli, and B. Zaitchik, 2020: A skewed perspective of the Indian rainfall-El Niño-Southern Oscillation (ENSO) relationship. Hydrol. Earth Syst. Sci., 24, 5473-5489, https:// doi.org/10.5194/hess-24-5473-2020.

Takahashi, K., A. Montecinos, K. Goubanova, and B. Dewitte, 2011: ENSO regimes: Reinterpreting the canonical and Modoki El Niño. Geophys. Res. Lett., 38, L10704, https:// doi.org/10.1029/2011GL047364.

Torrence, C., and G. P. Compo, 1998: A practical guide to wavelet analysis. Bull. Amer. Meteor. Soc., 79, 61-78, https://doi.org/ 10.1175/1520-0477(1998)079<0061:APGTWA > 2.0.CO;2.

— monsoon system. J. Climate, 12, 2679-2690, https://doi.org/ 10.1175/1520-0442(1999)012<2679:ICITEM > 2.0.CO;2.

Trenberth, K. E., and D. P. Stepaniak, 2001: Indices of El Niño evolution. J. Climate, 14, 1697-1701, https://doi.org/10.1175/ 1520-0442(2001)014<1697:LIOENO>2.0.CO;2.

Wang, M., Z. Guan, and D. Jin, 2018: Two new sea surface temperature anomalies indices for capturing the eastern and central equatorial Pacific type El Niño-Southern Oscillation events during boreal summer. Int. J. Climatol., 38, 4066-4076, https://doi.org/10.1002/joc.5552.

Wu, A., and W. W. Hsieh, 2003: Nonlinear interdecadal changes of the El Niño-Southern Oscillation. Climate Dyn., 21, 719-730, https://doi.org/10.1007/s00382-003-0361-1.

Yeh, S.-W., J.-S. Kug, B. Dewitte, M.-H. Kwon, B. Kirtman, and F.-F. Jin, 2009: El Niño in a changing climate. Nature, 461, 511-514, https://doi.org/10.1038/nature08316.

Yu, J. Y., and S. T. Kim, 2011: Relationships between extratropical sea level pressure variations and the central Pacific and eastern Pacific types of ENSO. J. Climate, 24, 708-720, https:// doi.org/10.1175/2010JCLI3688.1.

Yun, K. S., and A. Timmermann, 2018: Decadal monsoon-ENSO relationships reexamined. Geophys. Res. Lett., 45, 2014-2021, https://doi.org/10.1002/2017GL076912.

Zheng, F., and J.-Y. Yu, 2017: Contrasting the skills and biases of deterministic predictions for the two types of El Niño. $A d v$. Atmos. Sci., 34, 1395-1403, https://doi.org/10.1007/s00376-0176324-y. 